\title{
Mathematical modelling of Transient Free Convection MHD Flow Past a Vertical Plate with Periodic Temperature Using Homotopy Perturbation Method
}

\author{
E. Arul Vijayalakshmi ${ }^{1}$, M. Kannan ${ }^{1}$, and J Visuvasam ${ }^{2}$ \\ ${ }^{1}$ Government Arts College, Ariyalur, Affiliated to Bharathidasan University \\ ${ }^{2}$ Saraswathi Narayan College
}

September 29, 2020

\begin{abstract}
A mathematical model is used to study the effect of the magnetic field on the temporary free convection flow of the electrically conductive fluid past the vertical plate under periodic temperature. The governing momentum and energy equations are solved analytically using the homotopy perturbation method. An approximate analytical solution using Homotopy perturbation method and Laplace transform is carried out for temperature profile in case of constant plate temperature. The results are obtained the analytical and limiting case results ones, and a good agreement is achieved. The effect of different physical parameters on transient velocity and temperature, such as Grashof number, magnetic parameter, Prandtl number and temperature frequency, is examined. Also, the local Skin-friction and local Nusselt number coefficients are obtained and analyzed.
\end{abstract}

\section{Hosted file}

Manuscript-Visuvasam-28.pdf available at https://authorea.com/users/362793/articles/483819mathematical-modelling-of-transient-free-convection-mhd-flow-past-a-vertical-plate-withperiodic-temperature-using-homotopy-perturbation-method 